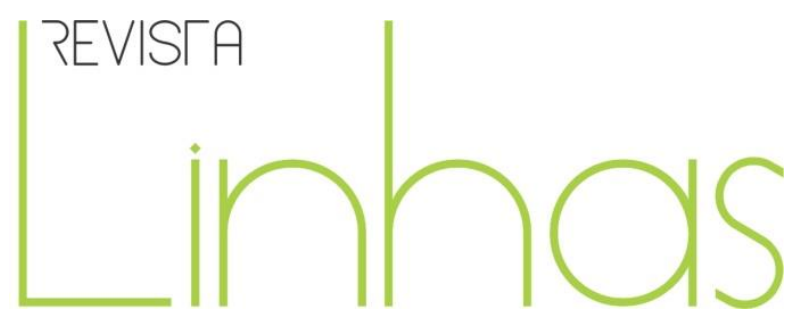

\title{
Tendências temáticas da pesquisa em Educação Hospitalar no Brasil: desafios e contribuições
}

\section{Resumo}

O objetivo deste artigo é identificar e analisar as principais tendências temáticas da pesquisa em Educação Hospitalar no Brasil. A metodologia é de natureza exploratória e descritiva, por meio de abordagem qualitativa do tipo bibliográfica, e baseou-se no catálogo de teses e dissertações produzidas em programas brasileiros de pósgraduação no campo da Educação Hospitalar no período de 2008 a 2017. Os resultados evidenciaram que estão sendo priorizadas as investigações relacionadas às temáticas do Desenvolvimento Humano, Educação e Humanização em Hospitais; Práticas Pedagógicas e Organização Didático-Curricular; e Formação de Professores. Verifica-se a presença de temáticas emergentes, como as Tecnologias Digitais da Informação e Comunicação e a Relação Educação e Saúde na Hospitalização. No entrecruzar dos dados, ressalta-se a necessidade de adesão a temáticas menos enfatizadas, como as Políticas Públicas na Educação Hospitalar; o Atendimento Pedagógico Domiciliar; e a Organização Pedagógica e Administrativa.
Roger Trindade Pereira

Universidade Federal do Tocantins -

UFT - Palmas/TO - Brasil

rogertp@uft.edu.br

\section{Carmem Lucia Artioli Rolim}

Universidade Federal do Tocantins UFT - Palmas/TO - Brasil carmem.rolim@uft.edu.br

Palavras-chave: Pacientes hospitalizados - Educação. Pesquisa educacional. Educação e saúde.

\section{Para citar este artigo:}

PEREIRA, Roger Trindade; ROLIM, Carmem Lucia Artioli. Tendências temáticas da pesquisa em Educação Hospitalar no Brasil: desafios e contribuições. Revista Linhas. Florianópolis, v. 22, n. 48, p. 267-302, jan./abr. 2021. 


\title{
Thematic trends on Hospital Education research in Brazil: challenges and contributions
}

\begin{abstract}
This article aims to identify and analyze the main thematic tendencies of research about Hospital Education in Brazil. The methodology is exploratory and descriptive in nature, through a qualitative approach of the bibliographical type, and was based on the catalog of theses and dissertations produced in Brazilian graduate programs in the field of Hospital Education between 2008 and 2017. The results evidenced that the priority have been investigations related to the themes of Human Development, Education and Humanization in Hospitals; Pedagogical Practices and Didactic-Curricular Organization; and Teacher Training. We verified the presence of emerging themes, such as Information and Communication Digital Technologies and the Education/Health Relation in Hospitalization. Crosschecking the data, we highlight the need to explore less emphasized themes, such as Public Policies in Hospital Education; Home Pedagogical Service; and Administrative and Pedagogical Organization.
\end{abstract}

Keywords: Hospitalized patients - Education. Education research. Education and health. 


\section{Notas introdutórias}

A pesquisa está inserida no contexto do estudo Panorama da produção científica sobre Educação Hospitalar em programas de pós-graduação no Brasil, o qual teve como objetivo conhecer as tendências temáticas e metodológicas, bem como os principais resultados da pesquisa brasileira no contexto do atendimento educacional hospitalar e domiciliar. A fim de sistematizar o campo de pesquisa ${ }^{1}$ em Educação Hospitalar, este artigo apresenta um mapeamento de teses e dissertações abordando as especificidades do atendimento educacional hospitalar e domiciliar, assim como traz em seu escopo o panorama das principais tendências temáticas de investigação.

A importância da Educação Hospitalar está relacionada, principalmente, com a manutenção do direito ao desenvolvimento da pessoa em tratamento, conectando as áreas da saúde e da educação. Sendo assim, mesmo em situação de internação hospitalar ou recuperação domiciliar, a Educação Hospitalar oportuniza que crianças e adolescentes não interrompam o seu processo de escolarização. Nessa perspectiva, por sua natureza interdisciplinar, é oportuno ressaltar também a possibilidade de ressignificar a relação com a doença, de modo a reduzir os efeitos traumáticos que podem advir da internação e da alteração da rotina familiar e escolar (FONTES, 2005; MATOS; MUGIATTI, 2014).

A Educação Hospitalar contempla, no seu campo de análise, a adoção de concepções pedagógicas que constituem fatores de influência nas possibilidades temáticas de investigação para determinado contexto educativo. Em vista disso, no hospital, os aspectos da aprendizagem e da humanização devem ocupar posição relevante no cotidiano do alunado, mesmo no ambiente primordialmente destinado à recuperação do aluno-paciente.

Essa importante característica pedagógica das atividades educacionais em contexto hospitalar, por vezes, até mesmo no domiciliar, implica ao campo de pesquisa a necessidade de proposições interdisciplinares de investigação, especialmente a partir de

\footnotetext{
${ }^{1}$ Como campo de pesquisa, compreende-se o processo de produção do próprio conhecimento teóricoconceitual, de constituição do espaço da educação enquanto atividade epistemológica de apreensão do real, ao mesmo tempo em que, permeado por normatividades, conflitos e contradições, refere-se às condições amplas e específicas da Educação Hospitalar que constituem o objeto para o desenvolvimento desta pesquisa, ou seja, o contexto em que se insere e prospera a atividade científica (GATTI, 2012; MINAYO, 2001).
} 
iniciativas de profissionais da educação e da saúde. Nesse contexto, as investigações científicas passam a ser possíveis na medida em que são capazes de se inserir em uma rede social de múltiplas relações envolvendo situações complexas, como o trabalho em equipe multiprofissional, os aspectos éticos da pesquisa com crianças e do ambiente hospitalar, a relação com a família do aluno-paciente e os limites de intervenção condicionados ao estado de saúde da criança.

Dessa forma, os processos investigativos ligados ao atendimento pedagógico hospitalar e domiciliar prosperam do entendimento da "[...] intersubjetividade criada no processo de negociação do conhecimento como forma de conhecer e não como natureza das coisas é um processo de recontextualização do cotidiano" (MATTOS, 2012 apud TAVARES, 2012, p. 127, grifos da autora). Neste caso, no campo da Educação Hospitalar, credita-se, como ponto de partida, que o conhecimento deve ser adquirido não somente a partir de seus produtos, mas também por meio de seus processos (SEVERINO, 2016).

Essa incursão nos processos de investigação, à medida que se busca identificar os principais enfoques temáticos a partir do contexto da produção de teses e dissertações, proporciona um panorama do comportamento científico. Assim, oportuniza também desvelar lacunas e desafios do conhecimento na Educação Hospitalar sob pontos de vista de diversos contextos, promovendo visão ampla e profunda daquilo que tem sido pesquisado.

Partindo dessas reflexões, define-se como objetivo identificar e analisar as principais tendências temáticas presentes no campo de pesquisa da Educação Hospitalar no Brasil, mediante o exame da produção acadêmica de teses e dissertações disponíveis na Biblioteca Digital Brasileira de Teses e Dissertações (BDTD).

Nesse contexto da produção científica, a partir das tendências temáticas de maior amplitude nos trabalhos científicos, percebe-se que, por um lado, é notável a presença de diversidade e interdisciplinaridade temática no campo de pesquisa, por outro, também se constata que tais estudos ainda possuem temas incipientes e pouco contemplados nos programas de pós-graduação no país. Com efeito, enquanto campo de investigação e produção de conhecimento, as tendências temáticas fornecem abordagens e diretrizes inovadoras à equipe multiprofissional e às práticas educativas no atendimento pedagógico hospitalar e domiciliar. 


\section{Delinear metodológico}

A investigação consistiu em uma proposta metodológica de natureza exploratória e descritiva. Quanto à abordagem do problema, assumiu-se a pesquisa qualitativa. Com referência ao processo de coleta e análise de dados, utilizou-se a pesquisa bibliográfica (GIL, 2010), cuja técnica de tratamento dos resultados decorre da análise de conteúdo (BARDIN, 2016).

Como primeira etapa, delineou-se um mapeamento bibliográfico, com vistas a incrementar e delimitar padrões temáticos de observação anteriormente desenvolvidos em outros estudos de revisão no campo da Educação Hospitalar. Desse estreitamento no campo de pesquisa foi possível definir inicialmente oito categorias temáticas, quais sejam: 1) Políticas Públicas na Educação Hospitalar; 2) Desenvolvimento Humano, Educação e Humanização em Hospitais; 3) Práticas Pedagógicas e Organização Didático-Curricular; 4) Atendimento Pedagógico Domiciliar; 5) Organização Pedagógica e Funcionamento Administrativo; 6) Tecnologias Digitais da Informação e Comunicação (TICs); 7) Formação de Professores; e 8) Relação Educação e Saúde na Hospitalização.

Após a definição das categorias temáticas, realizou-se o levantamento bibliográfico de teses e dissertações por meio da base de dados digitais da BDTD para formação do corpus bibliográfico da pesquisa. O levantamento bibliográfico de teses e dissertações contemplou o período de 2008 a 2017, sendo empregados no sistema de busca os seguintes descritores: “educação hospitalar”, “pedagogia hospitalar”, “atendimento pedagógico domiciliar" e “classe hospitalar”.

Assim, com a finalidade de delimitar o objeto de estudo, considerou-se como critérios de inclusão teses e dissertações que apresentaram problemas ou objetivos de pesquisa, geral ou específicos, diretamente relacionados com a Educação Hospitalar ou com temas referentes aos processos educativos em ambiente hospitalar e domiciliar.

Tendo por base esses critérios, realizou-se a leitura sistemática do resumo, introdução e metodologia, avaliando a centralidade da Educação Hospitalar enquanto problemática e objeto de estudo (SEVERINO, 2016). Tal caminho permitiu excluir alguns trabalhos do levantamento inicial, nos quais a Educação Hospitalar não se manifestou enquanto processo educativo. 
Na sequência dessa filtragem, alcançou-se o produto deste levantamento com os seguintes resultados: 79 pesquisas para integrar o corpus bibliográfico, conforme o anexo A, sendo compostas por 14 teses e 65 dissertações. Com base na sistematização e interpretação deste levantamento, iniciou-se a análise do conteúdo temático das 79 pesquisas por meio de oito categorias temáticas previamente definidas na revisão de literatura, buscando inferência com os padrões convergentes aos objetivos de investigação propostos nas teses e dissertações para elaboração de subtemas, ou seja, subcategorias de análise e discussão.

Dessa análise de conteúdo temático sobre as 79 pesquisas emergiram 20 subtemas, dispostos em oito categorias temáticas, conforme o Quadro 1. A proposta de discussão a partir de subtemas busca assegurar os limites de conteúdo entre as categorias, proporcionando uma análise mais sistemática e esclarecedora, traçando um panorama do conhecimento no conjunto das pesquisas. Sendo assim, cada tendência temática teve seus objetivos, contribuições e análises especificadas, tanto nas categorias temáticas da pesquisa quanto nas categorizações para cada subtema de estudo.

Portanto, propôs-se um minucioso exame bibliográfico essencialmente interpretativo e, na perspectiva de Bardin (2016) e Franco (2018), predominantemente dedutivo, pois o processo de análise do conteúdo temático foi operacionalizado com base em conhecimentos prévios, no campo manifesto das determinações da revisão de literatura e da inferência de conteúdo nas pesquisas. Entre as diversas possibilidades de categorização das teses e dissertações coligidas no corpus bibliográfico de análise deste estudo, compreendeu-se que as categorias temáticas de análise se constituíram a priori, sendo que os subtemas foram determinados a posteriori, ou seja, emergiram do conteúdo no decorrer do desenvolvimento da exploração e interpretação das teses e dissertações.

Para tanto, abordou-se como referência principal as orientações para categorização temática das pesquisas com base nas seguintes proposições:

A categorização de um trabalho em eixos temáticos é um processo complexo e que exige um olhar atento, especialmente pela multiplicidade de enfoques, abordagens e metodologias que geralmente se manifestam no conjunto de trabalhos pesquisado. Este conjunto 
raramente se apresenta de forma estanque e claramente definido no que tange à configuração das categorias temáticas, e a superposição de temas muitas vezes não pode ser evitada. Isso ocorre porque as categorias temáticas naturalmente não se mostram claramente disjuntas entre si, possibilitando muitas vezes que uma mesma pesquisa se enquadre em duas ou mais categorias, o que, por sua vez, dificulta um inquérito mais objetivo sobre o material pesquisado. (SANTOS, 2015, p. 47)

Em vista disso, para a obtenção dos dados, o processo de categorização transcorreu com a identificação das tendências temáticas de cada uma das teses e dissertações por meio da elaboração de fichas de conteúdo das pesquisas. Na sequência, planilhas foram organizadas a partir das categorias temáticas identificadas em suas fichas de leitura, bem como por meio das constantes leituras e releituras das teses e dissertações.

Enquanto análise de conteúdo, por meio de inferência nas categorias temáticas e respectivos subtemas, seguiu-se a proposta metodológica de sistematização e análise das teses e dissertações com a finalidade de evidenciar as principais contribuições, implicações e observações suscitadas por elas em relação às práticas educativas e terapêuticas e à pesquisa no contexto da Educação Hospitalar.

\section{Panorama das principais tendências temáticas no campo de pesquisa em Educação Hospitalar}

Visando traçar o panorama geral das pesquisas, a análise buscou proporcionar melhor visualização descritiva das teses e dissertações, detidas nas principais tendências temáticas do campo de pesquisa. Com isso, o Quadro 1 foi organizado em oito categorias temáticas e seus respectivos subtemas, acompanhados da distribuição de frequências das categorias temáticas. Ademais, devidamente discriminadas por nível acadêmico (doutorado, mestrado acadêmico e mestrado profissional), foi possível identificar os estudos mais recorrentes e os menos enfatizados. 
Quadro 1 - Distribuição das categorias temáticas e subtemas presentes nas pesquisas de Educação Hospitalar produzidas em programas brasileiros de pós-graduação (2008 a 2017)

\begin{tabular}{|c|c|c|c|c|}
\hline \multirow{2}{*}{ Tendências Temáticas } & \multicolumn{4}{|c|}{ Quantidade $^{2}$} \\
\hline & TE & DA & DP & Total \\
\hline Políticas Públicas na Educação Hospitalar & 0 & 2 & 1 & 3 \\
\hline Trajetória das políticas públicas & 0 & 1 & 1 & 2 \\
\hline Fundamentos históricos, teóricos e legais & 0 & 1 & 0 & 1 \\
\hline $\begin{array}{c}\text { Desenvolvimento Humano, Educação e Humanização em } \\
\text { Hospitais }\end{array}$ & 1 & 11 & 1 & 13 \\
\hline Brincar como estratégia de cuidado e enfrentamento da doença & 1 & 5 & 1 & 7 \\
\hline $\begin{array}{l}\text { Adoecimento e hospitalização infanto-juvenil: significados e } \\
\text { representações }\end{array}$ & 0 & 6 & 0 & 6 \\
\hline Práticas Pedagógicas e Organização Didático-Curricular & 1 & 20 & 0 & 21 \\
\hline $\begin{array}{l}\text { Atendimento pedagógico hospitalar: percepção do alunado e } \\
\text { acompanhantes responsáveis }\end{array}$ & 0 & 2 & 0 & 2 \\
\hline $\begin{array}{l}\text { Atendimento pedagógico hospitalar: percepção das } \\
\text { profissionais da educação }\end{array}$ & 0 & 7 & 0 & 7 \\
\hline Atendimento pedagógico hospitalar: componentes curriculares & 1 & 5 & 0 & 6 \\
\hline Lúdico como recurso pedagógico na classe hospitalar & 0 & 5 & 0 & 5 \\
\hline Panorama das atividades pedagógicas em ambiente hospitalar & 0 & 1 & 0 & 1 \\
\hline Atendimento Pedagógico Domiciliar & 1 & 1 & 1 & 3 \\
\hline $\begin{array}{l}\text { Atendimento pedagógico domiciliar: percepção dos sujeitos } \\
\text { envolvidos }\end{array}$ & 1 & 0 & 1 & 2 \\
\hline Lúdico como recurso pedagógico domiciliar & 0 & 1 & 0 & 1 \\
\hline Organização Pedagógica e Funcionamento Administrativo & 0 & 5 & 0 & 5 \\
\hline Implantação de classe hospitalar & 0 & 2 & 0 & 2 \\
\hline Organização e funcionamento de classe hospitalar & 0 & 3 & 0 & 3 \\
\hline Tecnologias Digitais da Informação e Comunicação (TICs) & 3 & 6 & 0 & 9 \\
\hline Ambiente Virtual de Aprendizagem (AVA) & 1 & 4 & 0 & 5 \\
\hline Aspectos pedagógicos das TICs & 2 & 2 & 0 & 4 \\
\hline Formação de Professores & 5 & 7 & 1 & 13 \\
\hline Formação inicial e continuada de professores & 2 & 4 & 1 & 7 \\
\hline $\begin{array}{l}\text { Saberes pertinentes à docência no atendimento pedagógico } \\
\text { hospitalar }\end{array}$ & 3 & 3 & 0 & 6 \\
\hline Relação Educação e Saúde na Hospitalização & 3 & 9 & 0 & 12 \\
\hline Equipe multiprofissional no atendimento pedagógico hospitalar & 1 & 2 & 0 & 3 \\
\hline Atenção lúdico-terapêutica & 2 & 3 & 0 & 5 \\
\hline $\begin{array}{l}\text { Atendimento pedagógico hospitalar: percepção de profissionais } \\
\text { da saúde }\end{array}$ & 0 & 4 & 0 & 4 \\
\hline Total & 14 & 61 & 4 & 79 \\
\hline
\end{tabular}

Fonte: Dados da pesquisa organizados pelos autores.

2 As abreviações TE/DA/DP significam, respectivamente, Tese/Dissertação Acadêmica/Dissertação Profissional. 
A seguir, por intermédio dos dados dispostos no Quadro 1, salienta-se o mapeamento temático descrevendo e examinando as teses e dissertações vinculadas conforme suas temáticas de discussão. Os resultados foram organizados por meio de categorias temáticas e discutidos em subtemas com a finalidade de sistematizar o conhecimento no conjunto da produção. Portanto, para cada categoria temática evidenciou-se uma síntese das principais contribuições e implicações decorrentes das conclusões e recomendações dessas pesquisas para as práticas educativas e estudos científicos no âmbito da Educação Hospitalar no país.

Na categoria temática Políticas Públicas na Educação Hospitalar, foram reunidas pesquisas com objetivos direcionados a verificar a trajetória dos documentos legais, buscando-se compreender os desafios e as contribuições das políticas públicas voltadas ao atendimento pedagógico hospitalar. Essa produção apresentou quantitativo reduzido de pesquisas, sendo somente três dissertações, as quais foram inferidas nos subtemas: Trajetória das políticas públicas, com duas dissertações; e Fundamentos históricos, teóricos e legais, com apenas uma dissertação.

No subtema Trajetória das políticas públicas, foram analisados os enunciados de alguns documentos oficiais brasileiros, tais como a Política Nacional de Educação Especial (BRASIL, 1994), Direitos da Criança e do Adolescente Hospitalizados (BRASIL, 1995), Resolução CNE/CEB n. 01/2011 (BRASIL, 2011), documento Classe Hospitalar e Atendimento Pedagógico Domiciliar: estratégias e orientações (BRASIL, 2002). No subtema Fundamentos históricos, teóricos, legais e técnicos, a única dissertação objetivou verificar a existência da Educação Hospitalar em Recife e região metropolitana, no estado de Pernambuco.

Constatou-se nas pesquisas que as classes hospitalares funcionam como um investimento social para a população infantil, ao passo que a escolarização, sendo um direito da criança hospitalizada, não pode deixar de fazer parte da vida do alunado, mesmo durante o período de internação hospitalar para tratamento de saúde (GONÇALVES, 2014; WEBER, 2009).

Na categoria Desenvolvimento Humano, Educação e Humanização em Hospitais, as pesquisas realizadas buscaram destacar o atendimento pedagógico hospitalar como um recurso de promoção da saúde e de cuidado integral do alunado hospitalizado. 
Ademais, não somente sobre os aspectos biológicos da patologia e seu tratamento, como também suas repercussões e representações emocionais, espirituais, escolares e sociais. As sondagens com enfoque temático no Desenvolvimento Humano, Educação e Humanização em Hospitais apresentaram significativo interesse dos pesquisadores, alcançando treze pesquisas, sendo uma tese e doze dissertações.

Como recurso de análise, foram elencamos dois subtemas, sendo eles: Brincar como estratégia de cuidado e enfrentamento da doença, composto por uma tese e seis dissertações; e o Adoecimento e hospitalização infanto-juvenil: significados e representações, com o restante das seis dissertações. Esse quantitativo releva a pertinência que representa mitigar os efeitos negativos de estar hospitalizado, tornando tal evento o menos traumático possível.

O subtema Brincar como estratégia de cuidado e enfrentamento da doença integrou pesquisas cujos objetivos tinham sustentação no cuidado integral, na promoção do bemestar das crianças e no pleno desenvolvimento de suas potencialidades por meio do brincar recreativo e terapêutico durante o período de hospitalização. As principais fontes de fundamentação teórica dessas pesquisas seguem como diretriz o Programa Nacional de Humanização da Assistência Hospitalar (PNHAH) (BRASIL, 2001), e autores que tratam do desenvolvimento dos aspectos lúdicos como promotor da aprendizagem, do desenvolvimento humano, social e cultural de crianças e adolescentes.

Esse subtema abordou questões bastante amplas que vão desde o atendimento pedagógico hospitalar como estratégia de enfretamento das incertezas relativas ao sucesso do tratamento de saúde e da redução da interação social (GARCIA-SCHINZARI, 2014; PACCIULIO, 2012; ZOMBINI, 2011); os efeitos negativos decorrentes do tratamento terapêutico (MOURA, 2013; PACCIULIO, 2012; ZOMBINI, 2011); as manifestações e representações do brincar durante a hospitalização (BATAGLION, 2016; GARCIASCHINZARI, 2014; HOCHMÜLLER, 2016); até avaliar os efeitos dos jogos sonoros no ambiente hospitalar (MIRANDA, 2017).

No subtema Adoecimento e hospitalização infanto-juvenil: significados $e$ representações, as pesquisas investigaram quem são as crianças hospitalizadas e como percebem os espaços de convivência a partir das experiências vividas no ambiente hospitalar. Diante disso, buscaram compreender sob as perspectivas das próprias 
crianças hospitalizadas suas representações, seus sonhos, suas opiniões e significados que atribuem a si mesmas e ao seu próprio mundo, como uma história autobiográfica da infância.

Em meio à hospitalização e ao adoecimento, os significados e representações dessas experiências foram possíveis e necessários para desvelar as marcas profundas nas memórias da infância. Em vista disso, os projetos destinados à humanização e à continuidade da escolarização, como a brinquedoteca e a classe hospitalar, ofereceram às crianças a possibilidade de ressignificar possíveis memórias negativas da hospitalização e da doença, ou seja, um processo de desenvolvimento humano inscrito nas relações sociais capaz de ir além do tratamento biomédico da enfermidade e projetar um novo futuro (BONATO, 2011; GEREMIAS, 2010; LOPER, 2011; ROCHA, 2012).

Na categoria temática destinada às Práticas Pedagógicas e Organização DidáticoCurricular, as pesquisas seguiram uma tendência de discussão sobre o atendimento pedagógico hospitalar a partir da percepção do alunado, acompanhantes responsáveis, profissionais da educação e de seus próprios componentes curriculares, bem como de seus desafios e possibilidades de concretização. Portanto, essa foi a tendência temática com o maior quantitativo de pesquisas produzidas dentre as categorias, totalizando 21 pesquisas, aproximadamente $28 \%$ do levantamento.

De tal modo, optou-se por discutir com base em cinco subtemas, segundo o Quadro 1, como recurso para melhor compreensão das experiências pedagógicas desenvolvidas em hospitais e obtidas sob o ponto de vista de seus diferentes atores.

Por intermédio do subtema Atendimento pedagógico hospitalar: percepção do alunado e acompanhantes responsáveis, duas dissertações discutiram a qualidade de vida das crianças hospitalizadas diante do atendimento pedagógico hospitalar por meio de suas próprias percepções e de seus acompanhantes responsáveis. Os resultados explicitaram a relevância de o atendimento pedagógico hospitalar considerar na sua realização aspectos ligados à condição clínica, à subjetividade no modo de compreender e enfrentar o processo de hospitalização do alunado e acompanhantes, ou seja, inclusive aquilo que se deixa de vivenciar (PASTEGA, 2016; STOCCHERO, 2012). 
No subtema Atendimento pedagógico hospitalar: percepção das profissionais da educação, as principais ideias norteadoras das discussões foram as características particulares do atendimento pedagógico hospitalar, especialmente com o objetivo de compreender significados, representações, experiências, demandas e saberes docentes. Esse subtema registrou o maior interesse temático desta investigação, comportando oito dissertações, ficando evidente a importância creditada ao trabalho docente no campo de pesquisa.

A percepção profissional das professoras indicou uma demanda por saberes que extrapolam a formação docente e alcançam suas próprias experiências e trajetórias de vida pessoal. Em vista disso, podemos destacar que os saberes docentes são plurais porque as professoras atribuem ao trabalho pedagógico o papel de apoio social que acumula representações e significados de figuras familiares e acompanhantes do alunado durante o período de hospitalização (ASSIS, 2009; CARVALHO, 2008; COMIN, 2009; SILVA, 2009).

Além do mais, outras preocupações sobrevêm do trabalho docente, tais como a situação socioeconômica do alunado, suas condições emocionais, a relação direta com a doença, a possibilidade de óbito, a necessidade de mediar relações de forma extrafamiliar e as dificuldades decorrentes da atuação conjunta com a equipe de saúde (ASSIS, 2009; CARVALHO, 2008; SOUZA, 2013). Essas características fazem do trabalho docente no contexto hospitalar algo desgastante o suficiente para também afetar a saúde física e emocional dessas profissionais.

Em razão da amplitude temática que envolve os resultados encontrados no subtema Atendimento pedagógico hospitalar: componentes curriculares, optou-se por priorizar a discussão especificamente quanto aos componentes curriculares (Língua Portuguesa, Educação Física, Artes Visuais, Ciências Naturais e Música) da Educação Básica (BRASIL, 2017), de modo integrado, contudo, preservando as especificidades e os saberes próprios construídos e sistematizados de cada área do conhecimento.

No subtema o Lúdico como recurso pedagógico na classe hospitalar, a produção destacou a importância das atividades lúdico-pedagógicas e lúdico-terapêuticas mediadas pelo trabalho docente na brinquedoteca e classe hospitalar. Outrossim, mais 
especificamente, buscaram compreender o papel do lúdico, situando-o como elemento mediador nos processos de aprendizagem do alunado no contexto hospitalar.

Essa ação educativa no ambiente hospitalar proporciona ao alunado amadurecer a convivência com a doença, visto que necessita conversar sobre a doença e ser ouvido diante de suas angústias, proporcionando o conhecimento e a compreensão das relações que envolvem sua própria realidade diante dos procedimentos invasivos e dolorosos de um tratamento de saúde (CARDOSO, 2011; KOHN, 2010; MORGADO, 2011).

Contudo, advertem sobre os desafios enfrentados no âmbito lúdico-pedagógico, particularmente, quando a classe hospitalar ocupar ou compartilhar do mesmo espaço da brinquedoteca. Com isso, indicaram que uma das consequências de ambas ocuparem o mesmo espaço físico é que o alunado, acompanhantes responsáveis e equipe de saúde acabam por se equivocarem em relação aos objetivos do trabalho do docente e do profissional brinquedista ou diversionista, cujas áreas de atuação são distintas (CARDOSO, 2011; MORGADO, 2011).

No subtema Panorama das atividades pedagógicas em ambiente hospitalar, encontrou-se uma dissertação cujo objetivo foi apresentar o panorama das dissertações de mestrado brasileiras dedicadas à escolarização desenvolvida em ambiente hospitalar (1989-2008). No período em análise, as experiências educacionais em âmbito hospitalar seguiam o caminho do voluntariado por meio de instituições religiosas e associações não governamentais como principais promotores dessa prática, assim como o desenvolvimento da educação especial e pedagogia terapêutica (OLIVEIRA, 2010).

$\mathrm{Na}$ categoria temática Atendimento Pedagógico Domiciliar, as pesquisas procederam na discussão sobre as particularidades dos atendimentos em domicílios. Entretanto, não obtivemos resultado de nenhuma pesquisa que direcionasse atenção para o tema com exclusividade, mas somente com objetivos que contemplavam simultaneamente o atendimento hospitalar e domiciliar.

Na categoria supracitada, obtiveram-se somente três pesquisas, sendo uma tese e duas dissertações, evidenciando que tal temática ainda havia sido pouco explorada no campo de pesquisa da Educação Hospitalar. Em vista disso, os recursos de análise foram elencados em dois subtemas, respectivamente: Atendimento pedagógico domiciliar: 
percepção dos sujeitos envolvidos, composto por uma tese e uma dissertação; e o Lúdico como recurso pedagógico domiciliar, com apenas uma dissertação.

O subtema Atendimento pedagógico domiciliar: percepção dos sujeitos envolvidos, destacou o atendimento escolar hospitalar e domiciliar ofertado por secretarias estadual e municipal de educação. O principal resultado indicado nas pesquisas foi a necessidade de socialização do direito à educação que assegura a oferta do atendimento pedagógico domiciliar e, consequentemente, a mobilização e reivindicação deste pela sociedade, por conseguinte, estimulando a criação de novos serviços (JESUS, 2017; NAZARETH, 2012).

Outro fator indicado nas pesquisas que pode favorecer o aumento da oferta dessa modalidade de ensino foi a elaboração de políticas públicas intersetoriais por meio de convênios de cooperação técnica e financeira entre as secretarias municipais e estaduais de educação e saúde. Vale ressaltar que, inclusive, reforçaram o papel da escola regular de origem em detectar a necessidade do atendimento escolar domiciliar, reduzindo as perdas deste aluno com relação à aprendizagem por conta das restrições de saúde e acionando a respectiva secretaria de educação responsável pela etapa da Educação Básica (JESUS, 2017; NAZARETH, 2012).

O subtema Lúdico como recurso pedagógico domiciliar, com somente uma dissertação, destaca as concepções pedagógicas de professoras do atendimento pedagógico domiciliar acerca da utilização de jogos didáticos no ensino e aprendizagem de conceitos científicos das disciplinas de Ciências e Biologia, Física, Matemática e Química. Neste subtema, foi indicada a carência de oferta de formação continuada de professoras para lecionar no atendimento pedagógico domiciliar, pois os cursos habitualmente são destinados às deficiências específicas, não contemplando a modalidade de atendimento educacional em classes hospitalares e domicílios (SILVA, Margarete, 2014).

Diante do exposto, indicaram a pertinência de novos estudos que possam contribuir com a efetivação do atendimento escolar domiciliar às crianças e aos adolescentes não hospitalizados, mas que ainda assim estão impossibilitados de frequentar a escola por problemas de saúde. 
Na categoria temática Organização Pedagógica e Funcionamento Administrativo,

a produção em programas de pós-graduação tem dado destaque aos aspectos históricos, desafios, limites e possibilidades de implementação e funcionamento de uma classe hospitalar e outros ambientes hospitalares. Em tal categoria temática, obtiveram-se quatro dissertações. Como recurso de análise, foram organizadas em dois subtemas, respectivamente: Implantação de classe hospitalar, composto por duas dissertações; e Organização e funcionamento de classe hospitalar, também com duas dissertações.

O subtema Implantação de classe hospitalar destacou o processo de implementação de classe hospitalar em hospital infantil. Essas pesquisas versaram acerca de questões referentes ao processo de constituição, legitimação e implementação do direito à educação da criança e do adolescente hospitalizado por meio de atendimento pedagógico hospitalar. O processo de constituição da classe hospitalar tem encontrado suporte teórico e legitimação científica a partir de experiências pedagógicas objetos de pesquisas desenvolvidas durante o século $X X$.

Como forma de superar a resistência da escolarização nos hospitais, as propostas indicaram a realização de ações como convênios de cooperação técnica ou financeira com secretarias de educação e saúde, campanhas de divulgação, conscientização de escolas e famílias sobre os direitos à educação e os benefícios terapêuticos do atendimento pedagógico durante a hospitalização (GIANNONI, 2013; SILVA, 2008).

O subtema Organização e funcionamento de classe hospitalar buscou descrever os aspectos organizacionais e administrativos das classes hospitalares. Os resultados destacaram a evolução das políticas públicas destinadas ao atendimento pedagógico hospitalar. Em vista disso, embora o direito à Educação Hospitalar esteja assegurado em legislações recentes de cunho nacional, os aspectos de gestão e funcionamento não possuem regulamentação específica e ficam a critério de cada sistema de ensino.

Como recurso para aperfeiçoar as demandas de organização e funcionamento, as pesquisas indicaram a implementação da intersetorialidade entre as distintas áreas governamentais, otimizando espaços, serviços e o desempenho de cada política pública destinada à continuidade do processo de escolarização e à manutenção do vínculo escolar (MARES, 2016; PACCO, 2017). Assim, estimula-se a comunicação de diferentes gestores na elaboração de ações, visando ao desenvolvimento de espaços sistemáticos 
de discussão, de natureza participativa e democrática, capazes de consolidar políticas públicas educacionais.

Na categoria temática Tecnologias Digitais da Informação e Comunicação, as pesquisas abordaram os procedimentos pedagógicos ligados ao desenvolvimento de Ambiente Virtual de Aprendizagem (AVA) para escolares hospitalizados. No âmbito dos AVAs, foram identificadas pesquisas pertinentes aos limites e às possibilidades de plataformas educativas no contexto hospitalar, tais como EUREK@Kids; Eduquito; Blog Cor@gem; e Blogs.

No caso mais específico, as tecnologias digitais da informação e comunicação (TDICs) ampliaram a sala de aula, ou seja, permitiram maior interação com o mundo físico, mesmo que o sujeito esteja em ambiente de exclusão social por conta das circunstâncias adversas do adoecimento.

No contexto do subtema Ambiente Virtual de Aprendizagem, obtiveram-se uma tese e quatro dissertações, as quais investigaram o desenvolvimento de AVAs e suas possibilidades educativas para alunos hospitalizados. Essas pesquisas destacaram a utilização de recursos pedagógicos digitais e da internet para mediar o processo de aprendizagem do aluno hospitalizado, favorecendo a manutenção do vínculo com a sala de aula e a oportunidade de seguir acompanhando as atividades letivas da escola regular (GARCEZ, 2009; KOWALSKI, 2008; RODACOSKI, 2009).

As experiências com os AVAs estimularam a autoestima e a confiança com efeitos motivadores à continuidade do tratamento terapêutico, sendo ferramentas mediadoras que amenizam as implicações negativas da hospitalização e do afastamento do convívio social, oportunizando a continuidade do processo de escolarização, mesmo que de maneira parcial (BATISTA, 2013; GARCEZ, 2009; MORO, 2011).

O subtema Aspectos pedagógicos das TICs contemplou duas teses e duas dissertações, privilegiando o exame de utilização das TCls nos aspectos pedagógicos que envolvem a escolarização hospitalar, bem como a validação de material pedagógico virtual. Os principais resultados apontaram que as TICs exerceram no apoio à mediação pedagógica a capacidade de facilitar a adequação curricular e o atendimento educativo individualizado, promovendo recursos de acessibilidade diante de restrições de 
mobilidade física e a ludicidade como estratégia de aprendizagem e comunicação terapêutica entre aluno e equipe hospitalar (CASTRO, 2010; FRANÇA, 2009; SILVA, Maria, 2014).

Outros aportes das TICs estiveram ligados à perspectiva do ambiente hospitalar como espaço de inclusão tecnológica e digital, capaz de promover aquisição de conhecimentos e construções afetivas, mesmo diante da doença, sem perder o potencial de desenvolvimento humano (FRANÇA, 2009; SANT’ANA, 2014; SILVA, Maria, 2014). Contudo, os resultados não demonstraram a percepção consistente sobre a utilização das TICs na prática docente no contexto hospitalar, especialmente porque os cursos de formação inicial ainda não desenvolvem conhecimentos suficientes à inserção de tecnologias educacionais neste espaço.

Na categoria temática Formação de Professores, foram reunidas as pesquisas que buscaram conhecer o campo de estudo ligado à formação de professores e os saberes necessários à construção da prática docente para atuar no atendimento pedagógico hospitalar. A formação de professores representa uma preocupação histórica do campo de pesquisa, bem como ocupa posição de destaque nas principais discussões acadêmicas sobre a educação no país.

Na categoria temática em voga, encontraram-se treze pesquisas. A análise dessa produção foi organizada em dois subtemas, respectivamente: Formação inicial $e$ continuada de professores, composto por duas teses e cinco dissertações; e Saberes pertinentes à docência no atendimento pedagógico hospitalar, disposto em duas teses e quatro dissertações.

As pesquisas conexas à Formação inicial e continuada de professores discutiram a construção e avaliação de propostas de formação continuada de professores para atuar na escolarização hospitalizada, como também ressignificar a prática pedagógica e as experiências de atendimento e acompanhamento do alunado no ambiente hospitalar. Os resultados mostraram um panorama do conhecimento sobre a formação de professores ainda insuficiente frente aos grandes desafios da inclusão escolar no país.

Por essa perspectiva, constatou-se nas teses e dissertações sugestões para o aperfeiçoamento dos cursos de formação inicial e continuada de professores no tocante 
às especificidades do atendimento hospitalar, dentre as quais algumas ideias norteadoras obtiveram destaque: a) construção de uma identidade própria do professor hospitalar; b) compreensão do processo de adoecimento como algo biopsicossocial; c) intervenção pedagógica destinada ao acolhimento da família e da criança; d) valorização das experiências e saberes docentes específicos depreendidos ao longo do exercício da prática educativa em hospitais; e) capacitação para utilização de tecnologias digitais como recurso pedagógico; f) construção de projeto político-pedagógico interdisciplinar; g) dificuldade em distinguir as diversas terminologias que conceituam o atendimento pedagógico hospitalar; h) estudos para identificar as razões do distanciamento entre secretarias de educação, saúde e hospitais; e i) fomento de eventos destinados à discussão de políticas e diretrizes educacionais em hospitais (BONFIM, 2016; BRANCO, 2008; FORTE, 2009; MAZER-GONÇALVES, 2013; OLIVEIRA, 2016; SANTOS, 2011; SILVA, 2012).

Dentro do subtema Saberes pertinentes à docência no atendimento pedagógico hospitalar, as pesquisas buscaram investigar a construção do conhecimento acerca da aprendizagem da docência em contextos hospitalares, assim como a atuação do pedagogo no acompanhamento pedagógico em âmbito hospitalar. Os principais resultados destacaram o papel mediador social que o docente assume entre o hospital, a escola, a família e o paciente. Essa mediação pedagógica também possibilita a aprendizagem, a continuidade no processo de desenvolvimento humano e o tratamento de saúde do aluno-paciente (CARVALHO, 2009; TAVARES, 2012).

Foram identificados ainda outros aspectos relevantes da mediação pedagógica ligados aos saberes específicos durante o período de hospitalização: a) a possibilidade de facilitar a adaptação de chegada (ação diagnóstica) e saída (ação prognóstica) do hospital, tornando-a mais suportável e menos traumática; b) a valorização dos aspectos afetivos, emocionais, biológicos e não só os aspectos cognitivos; c) o respeito e a empatia pelo momento de doença do aluno-paciente; d) o estímulo pela compreensão, aceitação e superação da condição de enfermo; e) o esclarecimento ao alunado acerca das políticas de Educação Especial e dos marcos legais que asseguram o direito à educação como recurso para trazer maior credibilidade e visibilidade ao trabalho pedagógico desenvolvido nos hospitais (CARVALHO, 2009; LIMA, 2010; LUCON, 2015; MEINEM, 2012). 
Evidenciou-se que os saberes específicos constituem os conteúdos subjetivos que precisam ser compreendidos como integrantes essenciais para a formação inicial de professores, preferencialmente quando se tratar da Educação Hospitalar, de modo que essa formação seja desenvolvida no próprio ambiente hospitalar por conta da dinâmica de negociações de sentidos atribuídos às ações pedagógicas entre professor e equipe de saúde (MEINEM, 2012; TAVARES, 2012).

Do ponto de vista investigativo, os resultados demonstraram a necessidade de novas pesquisas que contemplem os aspectos da intersubjetividade da própria prática como construção de autonomia no espaço da docência, ou seja, a possibilidade de investigação com olhar diferenciado e escuta sensível sobre as necessidades implícitas e específicas de atuação e formação docente (COVIC, 2008; LIMA, 2010; LUCON, 2015).

Na categoria temática Relação Educação e Saúde na Hospitalização, levando em conta o exposto até o momento, torna-se importante reafirmar que, embora a saúde do alunado seja a primeira preocupação no hospital, o próprio conceito de saúde não se restringe somente à integridade física, pois faz menção também à integridade psíquica e social da criança. Portanto, as pesquisas buscaram descrever o atendimento pedagógico hospitalar desenvolvido por equipe multiprofissional ou de profissionais da saúde e, ao mesmo tempo, examinar aspectos da ludicidade, da receptividade do alunado diante das atividades educativas e a realidade dessas crianças com foco na confluência entre os processos de aprendizagem e terapêutico.

Dentro dessas diretrizes interdisciplinares entre educação e saúde, foram encontradas doze pesquisas, sendo três teses e nove dissertações. Os subtemas desta categoria foram organizados por meio de três eixos de discussão: a) equipe multiprofissional no atendimento pedagógico hospitalar, com uma tese e duas dissertações; b) atenção lúdico-pedagógica, com duas teses e três dissertações; e c) atendimento pedagógico hospitalar: percepção de profissionais da saúde, com quatro dissertações.

No subtema Equipe multiprofissional no atendimento pedagógico hospitalar, o conjunto da produção buscou descrever e analisar o atendimento pedagógico hospitalar realizado por meio de equipe formada por profissionais da educação e saúde. Essas pesquisas destacaram as atividades práticas das intervenções realizadas em equipe 
multiprofissional na promoção da aprendizagem e, principalmente, na redução dos efeitos nocivos à saúde decorrentes de sua hospitalização prolongada.

Nas investigações citadas, as principais considerações dispostas indicaram que o atendimento pedagógico educacional realizado por equipe multiprofissional hospitalar promove redução de agravos decorrentes do tratamento de saúde. Identificaram-se, por conseguinte, outros aspectos relevantes no contexto hospitalar, tais como: melhor adaptação ao ambiente hospitalar e aceitação do tratamento de saúde, consequentemente o aumento do bem-estar devido à redução do estresse e de possíveis efeitos colaterais, promovendo qualidade no processo de recuperação e póshospitalização ao retornar ao seu convívio escolar e social (ALVES, 2009; SOUSA, 2011).

O subtema Atenção lúdico-pedagógica, em geral, apresentou pesquisas voltadas à utilização de brinquedo terapêutico e oficinas pedagógicas com jogos. Os enfoques temáticos buscaram compreender as vivências e as respostas do alunado ao tratamento de saúde diante das atividades de atenção lúdico-terapêuticas, bem como a percepção dos profissionais da saúde quanto à prática do brinquedo terapêutico.

Em relação aos resultados evidenciados, pode-se destacar a utilização do brinquedo terapêutico como instrumento de humanização e cuidado qualificado à criança hospitalizada. Os resultados revelaram que o brinquedo terapêutico possibilita aos profissionais envolvidos no tratamento de saúde a compreensão dos sentimentos e das reações emocionais da criança, facilitando o diagnóstico destinado ao desenvolvimento de protocolos específicos para reduzir o estresse da hospitalização, bem como preparálas para possíveis procedimentos invasivos ou mesmo encorajá-las para enfrentar as condições clínicas mais adversas de saúde (BATISTA, 2017; CAMPOS, 2017; LEITE, 2012; SCAGGION, 2013).

Da mesma forma, destacaram a necessidade de superar o atendimento à criança centrado no modelo biomédico, com predominância de atividades técnicas e subordinadas aos preceitos da medicina, para um modelo de ação que valorize mais a relação multiprofissional e interdisciplinar (BATISTA, 2017; CAMPOS, 2017; LEITE, 2012; SCAGGION, 2013). Ressalta-se também o cuidado das pessoas envolvidas no atendimento - sejam elas a própria equipe, a criança e o acompanhante responsável - por meio de 
estratégias de gestão compartilhada, clínica ampliada, acolhimento, ambiência e comunicação coletiva, o que denota os aspectos fundamentais da humanização na saúde.

As pesquisas categorizadas no subtema Atendimento pedagógico hospitalar: percepção de profissionais da saúde abordaram aspectos pertinentes quanto à concepção e às representações sociais dos profissionais da saúde acerca do atendimento pedagógico, da humanização e do trabalho do pedagogo no ambiente hospitalar.

Os resultados apontaram que os profissionais da saúde reconhecem os benefícios do atendimento pedagógico no desenvolvimento cognitivo, social e afetivo do alunado, pois indicam auxiliar no processo de tratamento, atenuando o sofrimento e a dor, tornando-se essencial na promoção da saúde (MASCARENHAS, 2011; MORAES, 2013; XAVIER, 2012). Todavia, nesses estudos, os profissionais da saúde indicaram que os acompanhantes responsáveis desconheciam ou não acreditavam no direito de acesso ao atendimento pedagógico de classe hospitalar ou recreativo de brinquedoteca; e, não dispondo desses atendimentos, ficavam convencidos de que somente o atestado médico poderia resolver as questões escolares dos alunos-pacientes, naturalizando o afastamento da rotina escolar e a exclusão social (SANDRONI, 2011; XAVIER, 2012).

Essas percepções do ambiente hospitalar, por sua vez, eram acrescidas do entendimento das famílias, as quais identificavam o excesso de ociosidade, a ausência de atividades do cotidiano escolar e de promoção do desenvolvimento humano da criança durante o período de hospitalização, levando-as a buscar, por meios próprios, novas formas de enfrentar as perdas emocionais e escolares de seus filhos (MORAES, 2013; XAVIER, 2012).

\section{Notas finais}

Da perspectiva da Educação Hospitalar, enquanto campo de pesquisa, percebe-se que os pesquisadores partem da premissa de que é possível intervir cientificamente para elucidar teorias e práticas pautadas no processo de ensino-inclusão do ambiente hospitalar. Corroborando essa constatação, no que tange às contribuições no adensamento das tendências temáticas em questão, em síntese, destacam-se os 
principais resultados encontrados por intermédio das subcategorias temáticas propostas na análise das teses e dissertações:

- Políticas Públicas na Educação Hospitalar: o quantitativo de pesquisas atinentes às políticas públicas na Educação Hospitalar ainda é incipiente. Além da necessidade de novos estudos no tema, há a importância da elaboração de parcerias intersetoriais entre educação e saúde como instrumento de promoção de políticas públicas e caminho à efetivação do atendimento educacional hospitalar;

- Desenvolvimento Humano, Educação e Humanização em Hospitais: observou-se a relevância do ato pedagógico de brincar como estratégia de cuidado integral destinado à compreensão dos procedimentos terapêuticos e à redução dos efeitos negativos relacionados à hospitalização. Além disso, o brincar humanizado estimula no alunado o vínculo afetivo de confiança com a equipe de saúde, sua interação social com a família e colegas de leito/setor, proporcionando, assim, a manutenção do sentimento de vida. Em vista disso, acresce a pertinência de novos estudos com a finalidade de desvelar e orientar a condução de pesquisas com crianças no ambiente hospitalar;

- Práticas Pedagógicas e Organização Didático-Curricular: verificou-se que as professoras da classe hospitalar trabalham com diferentes saberes no ambiente hospitalar que extrapolam a função docente e alcançam dimensões relativas às próprias experiências e trajetórias de vida, de apoio social, familiar e acompanhante do alunado durante o período de hospitalização. Em relação aos componentes curriculares, os resultados foram incipientes, mas foram encontradas pesquisas sobre o atendimento pedagógico hospitalar relacionadas ao ensino de Língua Portuguesa, Educação Física, Artes Visuais, Ciências Naturais e Música. No entanto, pesquisas ligadas ao ensino da Matemática, História e Geografia no contexto hospitalar não foram encontradas no levantamento;

- Atendimento Pedagógico Domiciliar: na análise da produção foram encontrados resultados incipientes na modalidade domiciliar, inclusive não se obteve neste levantamento nenhuma pesquisa que abordasse com exclusividade o tema. A oferta dessa modalidade de ensino carece de divulgação social do direito à educação domiciliar, bem como enfrenta resistências da gestão pública por conta do seu elevado custo quanto à escola regular; 
- Organização Pedagógica e Funcionamento Administrativo: observou-se a necessidade de priorizar investigações quanto às demandas de pessoal e de infraestrutura para que sejam concretizados os espaços educacionais nos hospitais. Ademais, percebeu-se a busca por diretrizes e regulamentações específicas de âmbito nacional para orientar os procedimentos de gestão e implantação de classes hospitalares;

- Tecnologias Digitais da Informação e Comunicação: identificou-se que o emprego das TICs e dos AVAs no contexto hospitalar promove abertura, conexão e ampliação da realidade do alunado diante da situação de isolamento social proporcionada pela hospitalização. Diante da possibilidade de vínculo EaD com a escola regular, é possível destacar no alunado a recuperação de aspectos emocionais como a autoestima, confiança e motivação no prosseguimento do tratamento de saúde. Por isso, embora as TICs e os AVAs estimulem o bem-estar do alunado, não podem adquirir somente a configuração de atividade recreativa;

- Formação de Professores: a insuficiente formação inicial foi uma das reinvindicações mais preconizadas nas pesquisas em Educação Hospitalar, bem como a necessidade de a formação continuada ocorrer preferencialmente no próprio ambiente hospitalar. Outro ponto de destaque dessa temática foi a indicação de sugestões para o desenvolvimento e aperfeiçoamento dos cursos de formação de professores para atuar no contexto hospitalar;

- Relação Educação e Saúde na Hospitalização: observou-se que o atendimento educacional multiprofissional realizado entre profissionais da saúde e da educação beneficia a redução dos agravos decorrentes do tratamento prolongado de saúde. Para tanto, cresce de importância o esforço de aproximação e ação conjunta entre equipe hospitalar e a escola regular do alunado por meio de treinamentos em serviço, como também a oportunidade de diálogo sobre experiência e conhecimentos ligados à aprendizagem e ao cuidado do alunado hospitalizado ou domiciliado.

No que tange aos principais resultados das pesquisas, alguns estudos tiveram conclusões semelhantes, mesmo aquelas categorizadas em temáticas distintas. Observou-se essa convergência de resultados, por exemplo, na promoção de parcerias intersetoriais entre educação e saúde (LIMA, 2017; LOIOLA, 2013; NAZARETH, 2012), no entendimento de os professores disporem de formação específica para atuar na classe 
hospitalar (ASSIS, 2009; JESUS, 2017; LOIOLA, 2013; SALDANHA, 2012), no atendimento pedagógico como recurso para amenizar os efeitos negativos da hospitalização (CARVALHO, 2009; MIRANDA, 2017; STOCCHERO, 2012; ZOMBINI, 2011) e na utilização da escuta pedagógica como valorização da singularidade das expressões de vida do alunado (ALVES, 2009; COMIN, 2009; LOIOLA, 2013).

É possível destacar como desafios esperados para os próximos anos, o aumento da produção de pesquisas em todas as regiões do país, bem como a adesão de temas ainda pouco explorados como Políticas Públicas na Educação Hospitalar, Atendimento Pedagógico Domiciliar e Organização Pedagógica e Funcionamento Administrativo. Outro desafio a ser superado pelo campo de pesquisa é o reduzido quantitativo da produção de teses de doutorado, situação que, no período em análise da BDTD, apresentou a média de quatro teses/ano.

Em vista do exposto, indica-se que novos estudos serão necessários para aprofundar a discussão e contemplar outras vertentes temáticas de investigação, assim como contribuir com a compreensão dessa modalidade de ensino. Em suma, por meio do desenvolvimento da pesquisa, buscou-se atender o objetivo proposto e ainda estimular a discussão acadêmica sobre o ensino e a pesquisa em Educação Hospitalar no que tange às crianças e aos adolescentes hospitalizados ou domiciliados no país.

\section{Referências}

ALVES, Aldalice Braitt Lima. Implantação e avaliação de um conjunto de ações educativas desenvolvidas junto a pacientes pediátricos internados: a experiência do Hospital Manoel Novaes - Bahia. 214f. Tese (Doutorado em Educação), Programa de PósGraduação em Educação, Universidade Federal da Bahia, Salvador-BA, 2009.

ASSIS, Walkíria de. Atendimento pedagógico-educacional em hospitais: da exclusão à inclusão social/escolar. 120f. Dissertação (Mestrado em Educação), Faculdade de Educação, Universidade de São Paulo, São Paulo-SP, 2009. 
BARDIN, Laurence. Análise de conteúdo. São Paulo: Edições 70, 2016.

BATAGLION, Giandra Anceski. O lúdico na reabilitação de crianças com deficiência. $186 f$. Dissertação (Mestrado). Programa de Pós-Graduação em Educação Física, Centro de Desportos, Universidade Federal de Santa Catarina, Florianópolis, 2016.

BATISTA, Crassio Augusto. 0 uso do computador em rede telemática no processo de ensino e aprendizagem em classe-hospitalar: O PROUCA e o Eduquito promovendo a aprendizagem do aluno enfermo. 138f. Dissertação (mestrado em educação). Faculdade de Educação, Universidade de Brasília, Brasília-DF, 2013.

BATISTA, Anelice da Silva. Escolarização de crianças com doenças crônicas: "eu presto atenção no que eles dizem, mas eles não dizem nada". 105 f. Tese (Doutorado). Universidade de Brasília, Brasília, 2017.

BONATO, Cássia Aparecida Andrade. Estudo das representações de crianças internadas hospital sobre o adoecimento e a hospitalização em uma abordagem piagetiana. $148 \mathrm{f}$. Dissertação (Mestrado em Economia Doméstica), Universidade Federal de Viçosa, ViçosaMG, 2011.

BONFIM, Evandro Luiz Soares. Formação do pedagogo para atuar na classe hospitalar: desafios e perspectivas. 2016. 168f. Dissertação (Mestrado em Enfermagem), Escola Paulista de Enfermagem, Universidade Federal de São Paulo, São Paulo, 2016.

BRANCO, Rita Francis Gonzalez y Rodrigues. Capacitação de professores de Classe Hospitalar em relação professor-aluno/paciente na perspectiva balintiana. 180 . Tese (Doutorado em Educação), Universidade Federal de Goiás, Goiânia-Go, 2008.

BRASIL. Secretaria Nacional de Educação Especial. Política Nacional de Educação Especial. Brasília, DF: MEC; SEESP, 1994.

BRASIL. Conselho Nacional dos Direitos da Criança e do Adolescente. Direitos da criança e do adolescente hospitalizados: resolução $n^{\circ}$ 41, de 13 de outubro de 1995. [Brasília, DF: MEC], 1995. Disponível em: https://www.ufrgs.br/bioetica/conanda.htm. Acesso em: 17 dez. 2020.

BRASIL. Secretaria de Assistência à Saúde. Programa Nacional de Humanização da Assistência Hospitalar. Brasília, DF: Ministério da Saúde, 2001.

BRASIL. Secretaria de Educação Especial. Classe hospitalar e atendimento pedagógico domiciliar: estratégias e orientações. Brasília, DF: MEC; SEESP, 2002.

BRASIL. Resolução CNE/CEB nº 01 de 10 de março de 2011. Fixa normas de funcionamento das unidades de Educação Infantil ligadas à Administração Pública Federal direta, suas autarquias e fundações. [Brasília, DF: MEC], 2011. Disponível em: http://portal.mec.gov.br/todas-as-noticias/323-secretarias-112877938/orgaos-vinculados82187207/16416-resolucoes-ceb-2011. Acesso em: 7 dez. 2019. 
BRASIL. Resolução CNE/CP n 2/2017. Institui e orienta a implantação da Base Nacional Comum Curricular, a ser respeitada obrigatoriamente ao longo das etapas e respectivas modalidades no âmbito da Educação Básica. Diário Oficial da União: Seção 1, Brasília, DF, p. 41, 22 dez. 2017.

CAMPOS, Stefanny Maria Santana de. O brincar de faz de conta de crianças com câncer que se submetem ao processo de quimioterapia. 145f. Dissertação (Mestrado em Enfermagem). Escola de Enfermagem de Ribeirão Preto, Universidade de São Paulo, São Paulo, 2017.

CARDOSO, Mirelle Ribeiro. Desafios e possibilidades da ludicidade no atendimento pedagógico hospitalar. 134f. Dissertação (Mestrado em Educação), Programa de PósGraduação em Educação Universidade de Brasília, Brasília-DF, 2011.

CARVALHO, Ana Rosa R. Ferreira de. A classe hospitalar sob o olhar de professores de um hospital público infantil. 104f. Dissertação (Mestrado em Psicologia). Pontifícia Universidade Católica de São Paulo, São Paulo-SP, 2008.

\section{CARVALHO, Adnan de. A criança, o brincar e a aprendizagem no contexto}

Hospitalar. 136f. Dissertação (Mestrado em Educação), Programa de Pós-Graduação em Educação, Centro de Educação, Comunicação e Artes, Universidade Estadual de Londrina, Londrina-PR, 2009.

CASTRO, Amparito Del Rocío Vintimilla. Validação de conteúdo de sítio virtual sobre uso do brinquedo na enfermagem pediátrica. 18gf. Tese (Doutorado em Enfermagem), Universidade de São Paulo, São Paulo-SP, 2010.

COMIN, Juliana Oliveira. Os saberes docentes na classe hospitalar. 121f. Dissertação (Mestrado em Educação), Programa de Pós-Graduação em Educação, Centro de Ciências da Educação, Universidade Federal de Santa Catarina, Florianópolis-SC, 2009.

COVIC, Amália Neide. Aprendizagem da Docência: um estudo a partir do atendimento escolar hospitalar. 277f. Tese (Doutorado em Educação), Pontifícia Universidade Católica de São Paulo, São Paulo-SP, 2008.

FRANÇA, Cristiane Maria. Aspectos da formação do professor na mediação pedagógica na utilização das tecnologias da informação e comunicação na escolarização hospitalar. 152f. Dissertação (Mestrado em Educação), Programa de Pós-Graduação em Educação, Centro de Teologia e Ciências Humanas, Pontifícia Universidade Católica do Paraná, Curitiba-PR, 2009.

FRANCO, Maria Laura Puglisi Barbosa. Análise de conteúdo. 5. ed. Campinas: Editora Autores Associados, 2018.

FONTES, Rejane de S. A escuta pedagógica à criança hospitalizada: discutindo o papel da educação no hospital. Revista Brasileira de Educação, [on-line], n. 29, p. 119-138, 2005. 
FORTE, Luiza Tatiana. Mapa conceitual: um instrumento para formação docente de professores que trabalham com a escolarização no hospital para uma prática inovadora. 258f. Dissertação (mestrado). Programa de Pós-Graduação em Educação, Centro de Teologia e Ciências Humanas, Pontifícia Universidade Católica do Paraná, Curitiba-PR, 2009 .

GARCEZ, Claudia Rosane. Utilizando Blog e suas ferramentas para auxiliar a integrar o aluno paciente à escola: um estudo de caso na área de ciências. 106f. Dissertação (Mestrado em Educação). Programa de Pós-Graduação em Educação em Ciências e Matemática, Faculdade de Física, Pontifícia Universidade Católica do Rio Grande do Sul, Porto Alegre-RS, 2009.

GARCIA-SCHINZARI, Nathália Rodrigues. Análise do brincar de faz de conta de crianças pré-escolares com câncer. 135f. Dissertação (Mestrado). Escola de Enfermagem de Ribeirão Preto, Universidade de São Paulo, Ribeirão Preto, 2014.

GATTI, Bernardete Angelina. A construção metodológica da pesquisa em educação: desafios. Revista Brasileira de Política e Administração da Educação, Brasília, v. 28, n. 1, p. 13-34, jan./abr. 2012.

GEREMIAS, Tania Maria Fiorini. O contexto da educação hospitalar nas narrativas das crianças. 244f. Dissertação (Mestrado em Educação). Programa de Pós-Graduação em Educação, Centro de Ciências da Educação, Universidade Federal de Santa Catarina, Florianópolis-SC, 2010.

GIANNONI, Rosana M. A escola hospitalar do Hospital A. C. Camargo: uma experiência de humanização narrada por sua fundadora. 127f. Dissertação (Mestrado em Educação), Pontifícia Universidade Católica de São Paulo, São Paulo, 2013.

GIL, Antonio Carlos. Como elaborar projetos de pesquisa. 5. ed. São Paulo: Atlas, 2010.

GONÇALVES, Monica Feitosa de Carvalho Pedrozo. O serviço de educação infantil HU/UFSC frente à Resolução CNE/CEB nº 01/2011 (BRASIL, 2011). 107. Dissertação (Mestrado em Administração), Programa de Pós-Graduação em Administração Universitária do Departamento de Ciências da Administração da Universidade Federal de Santa Catarina, Florianópolis-SC, 2014.

HOCHMÜLLER, Caroline Schwerz de Oliveira. Experiências de crianças hospitalizadas: um estudo em um hospital do município de Cruz Alta - RS. 110f. Dissertação (Mestrado em Educação), Programa de Pós-Graduação em Educação nas Ciências, Universidade Regional do Noroeste do Estado do Rio Grande do Sul, ljuí, 2016.

JESUS, Edna Maria de. Desafios do atendimento pedagógico hospitalar/domiciliar em Goiás: gênero e docência no olhar dos/as agentes envolvidos/as. 206 f. Tese (Doutorado em Educação), Programa de Pós-Graduação Stricto Sensu em Educação, Pontifícia Universidade Católica de Goiás, Goiânia-GO, 2017. 
KOHN, Carla Daniela. Ludoterapia: uma estratégia da pedagogia hospitalar na ala pediátrica do hospital universitário da Universidade Federal de Sergipe. 125f. Dissertação (Mestrado em Educação), Núcleo de Pós-Graduação em Educação, Universidade Federal de Sergipe, São Cristóvão-SE, 2010.

KOWALSKI, Raquel Pasternak Glitz. Eurek@kids: uma experiência de uso de ambiente virtual de aprendizagem no processo ensino-aprendizagem em contexto hospitalar. $154 \mathrm{f}$. Dissertação (Mestrado em Educação), Programa de Pós-Graduação em Educação, Centro de Teologia e Ciências Humanas, Pontifícia Universidade Católica do Paraná, Curitiba-PR, 2008.

LIMA, Luci Fernandes de. Saberes necessários para atuação em Pedagogia Hospitalar. 9of. Tese (Doutorado em Educação), Programa de Pós-Graduação em Educação, Pontifícia Universidade Católica de São Paulo, São Paulo-SP, 2010.

LEITE, Tânia Maria Coelho. Trabalho do enfermeiro com crianças hospitalizadas e o uso do brinquedo terapêutico.141f. Tese (Doutorado em Enfermagem), Programa de PósGraduação em Enfermagem da Universidade Estadual de Campinas, Campinas-SP, 2012.

LOIOLA, Fernanda Cristina Feitosa. Subsídios para a educação hospitalar na perspectiva da educação inclusiva. 139f. Dissertação (Mestrado em Educação), Universidade Federal de Pernambuco, Recife, 2013.

LOPER, Adriane Aparecida. $O$ atendimento educacional de uma criança com necessidades especiais na UTI: ressignificando vivências. 101f. Dissertação (Mestrado em Educação), Programa de Pós-Graduação em Educação, Centro de Educação, Comunicação e Artes, Universidade Estadual de Londrina, Londrina-PR, 2011.

LUCON, Cristina Bressaglia. Representações docentes: o olhar para o aluno com mucopolissacaridose tipo VI do município de Monte Santo-BA. 278f. Tese (Doutorado em Educação), Universidade Federal da Bahia, Faculdade de Educação, Salvador, 2015.

MARES, Thaise Fernanda de Lima. 0 serviço de atendimento à rede de escolarização hospitalar do Hospital Universitário do Oeste do Paraná de Cascavel - PR: um estudo sobre os adolescentes atendidos na ala de desintoxicação. Dissertação (Mestrado em Educação), Universidade Estadual do Oeste do Paraná, Cascavel, 2016.

MASCARENHAS, Aline Daiane Nunes. Percepções de médicos sobre o papel do pedagogo no trabalho com crianças hospitalizadas: o caso do Hospital das Clínicas da UFBA. $183 f$. Dissertação (Mestrado em Educação), Programa de Pós-Graduação em Educação, Faculdade de Educação, Universidade Federal da Bahia, Salvador-BA, 2011.

MATOS, Elizete Lúcia Moreira; MUGIATTI, Margarida Maria Teixeira de Freitas. Pedagogia hospitalar: a humanização integrando educação e saúde. In: MATOS, Elizete Lúcia Moreira (Org.). 7. ed. Petrópolis: Vozes, 2014. 
MAZER-GONÇALVES, Sheila Maria. Construção de uma proposta de formação continuada para professores de classe hospitalar. 178f. Tese (Doutorado em Educação), Centro de Educação e Ciências Humanas, Universidade Federal de São Carlos, 2013.

MEINEM, Carina Vizzotto. Conteúdos Subjetivos da docência e a classe hospitalar. $233 \mathrm{f}$. Dissertação (Mestrado em Educação), Centro de Ciências da Educação, Programa de PósGraduação em Educação, Universidade Federal de Santa Catarina, Florianópolis-SC, 2012.

MINAYO, Maria Cecília de Souza. Pesquisa social: teoria, método e criatividade. 21. ed. Petrópolis: Vozes, 2001.

MIRANDA, Paulo César Cardozo de. Música e jogos sonoros: a experiência lúdica no ambiente hospitalar infantil humanizado. Tese (Doutorado em Comunicação), Escola de Comunicações e Artes, Universidade de São Paulo, São Paulo, 2017.

MORAES, Myrian Soares de. Brincando e sendo feliz: a pedagogia hospitalar como proposta humanizadora no tratamento de crianças hospitalizadas. 173f. Dissertação (Mestrado em Educação), Universidade Federal de Sergipe, 2013.

MORGADO, Fernanda Martimon. Classes hospitalares e seus recursos lúdicos: uma investigação com os atores sociais envolvidos. 189f. Dissertação (Mestrado em Educação), Faculdade de Educação, Universidade de Brasília, Brasília-DF, 2011.

MORO, Eliane Lourdes da Silva. Ambientes virtuais de aprendizagem e recursos da web 2.0 em contexto hospitalar: rompendo a exclusão temporária de adolescentes com fibrose cística. 233f. Tese (Doutorado em Educação), Programa de Pós-Graduação em Educação, Faculdade de Educação, Universidade Federal do Rio Grande do Sul, Porto Alegre-RS, 2011.

MOURA, Isis Ferraz de. O lúdico no hospital: um estudo teórico sobre atividades com crianças. 8gf. Dissertação (Mestrado Profissional em Educação Profissional em Saúde), Escola Politécnica de Saúde Joaquim Venâncio, Fundação Oswaldo Cruz, 2013.

NAZARETH, Cátia Aparecida Lopes. Educação hospitalar/domiciliar no município de Juiz de Fora - Minas Gerais. 108f. Dissertação (Mestrado em Políticas Públicas e Avaliação da Educação), Programa de Pós-Graduação Profissional em Gestão e Avaliação da Educação Pública, Universidade Federal de Juiz de Fora, Juiz de Fora-MG, 2012.

OLIVEIRA, Fabiana Aparecida de Melo. Projeto pedagógico hospitalar Escola Móvel Aluno Específico: cultura escolar e debate acadêmico (1989-2008). 287f. Dissertação (Mestrado em Educação), Programa de Pós-Graduação em Educação da Faculdade de Educação da Universidade Estadual de Campinas, Campinas-SP, 2010.

OLIVEIRA, Roberta Ceres Antunes Medeiros de. Narrativas de aprendizagens ao longo da vida: uma pesquisa-ação-formação com professoras de classes hospitalares. $162 \mathrm{f}$. Dissertação (Mestrado em Educação), Universidade Federal do Rio Grande do Norte, Centro de Educação, Programa de Pós-graduação em Educação, 2016. 
PACCIULIO, Amanda Mota. Estratégias de enfrentamento do tratamento quimioterápico na perspectiva de crianças com câncer hospitalizadas. 120f. Dissertação (Mestrado em Enfermagem), Escola de Enfermagem de Ribeirão Preto, Universidade de São Paulo, Ribeirão Preto-SP, 2012.

PACCO, Aline Ferreira Rodrigues. Panorama das classes hospitalares brasileiras: formação e atuação docente, organização e funcionamento. 158f. Dissertação (Mestrado em Educação Especial), Programa de Pós-Graduação em Educação Especial, Centro de Educação e Ciências Humanas, Universidade Federal de São Carlos - UFSCar, São Carlos, 2017.

PASTEGA, Mariana Gonçalves. A qualidade de vida da criança durante a internação hospitalar. 184f. Dissertação (Mestrado em Ciências da Saúde). Programa de Pós-graduação em Gestão da Clínica, Universidade Federal de São Carlos, São Carlos-SP, 2016.

ROCHA, Simone Maria da. Narrativas infantis: o que nos contam as crianças de suas experiências no hospital e na classe hospitalar. 163f. Dissertação (Mestrado em Educação), Programa de Pós-graduação em Educação, Centro de Educação, Universidade Federal do Rio Grande do Norte, Natal-RN, 2012.

RODACOSKI, Giseli Cipriano. A mediação pedagógica em um ambiente virtual de aprendizagem em contexto hospitalar. 154f. Dissertação (Mestrado em Educação), Programa de Pós-Graduação em Educação, Centro de Teologia e Ciências Humanas, Pontifícia Universidade Católica do Paraná, Curitiba-PR, 2009.

SALDANHA, Gilda Maria Maia Martins. A educação escolar hospitalar: práticas pedagógicas docentes com crianças em tratamento oncológico no Hospital Ophir Loyola em Belém-PA. 151f. Dissertação (Mestrado em Educação), Instituto de Ciências da Educação, Mestrado Acadêmico em Educação, Universidade Federal do Pará, Belém-PA, 2012.

SANDRONI, Giuseppina Antonia. Classe hospitalar: a importância do acompanhamento pedagógico para crianças e adolescentes. 105f. Dissertação (Mestrado em Educação Especial), Programa de Pós-Graduação em Educação Especial, Universidade Federal de São Carlos, 2011.

SANT'ANA, Alex Sandro Coitinho. O ser da presença da docência com o dispositivo tablet PC e as teias educacionais de aprendizagens inclusivas na [psico] pedagogia social hospitalar. 303 f. Tese (Doutorado em Educação), Centro de Educação, Universidade Federal do Espírito Santo, 2014.

SANTOS, Divina Ferreira de Queiroz. Formação do professor para a pedagogia hospitalar na perspectiva da educação inclusiva na rede municipal de Goiânia. 113f. Dissertação (Mestrado em Educação), Pontifícia Universidade Católica de Goiás, Goiânia-GO, 2011. 
SANTOS, Rodrigo Medeiros dos. Estado da arte e história da pesquisa em educação estatística em programas brasileiros de pós-graduação. 248 f. 2015. Tese (Doutorado em Educação), Faculdade de Educação, Universidade Estadual de Campinas, Campinas, 2015.

SCAGGION, Leslie Rose Esper. "Mas eu sabe tudo": compreendendo o mundo-vida da criança hospitalizada na unidade de terapia intensiva pediátrica por meio do brinquedo terapêutico. 141f. Dissertação (Mestrado em Enfermagem), Faculdade de Enfermagem, Universidade Estadual de Campinas, Campinas-SP, 2013.

SILVA, Juliana Motta de Assis. Um estudo sobre o processo de implementação de classes hospitalares: o caso do Hospital Boldrini. 192f. Dissertação (Mestrado em Educação), Faculdade de Educação, Universidade Estadual de Campinas, Campinas-SP, 2008.

SILVA, Maria Celeste Ramos da. A criança e o adolescente enfermos como sujeitos aprendentes: representações de professores da rede regular de ensino no município de Salvador-BA. 214f. Dissertação (Mestrado em Educação), Faculdade de Educação, Universidade Federal da Bahia, Salvador-BA, 2009.

SILVA, Giselli Cristiane da. A formação de professores e a utilização das mesas educacionais como meio pedagógico integrado à proposta de escolarização em contexto hospitalar. 116f. Dissertação (Mestrado em Educação), Programa de PósGraduação em Educação da Pontifícia Universidade Católica do Paraná, Curitiba-PR, 2012.

SILVA, Margarete Virgínia Gonçalves. A utilização dos jogos didáticos em novos segmentos da educação: a prática pedagógica do professor no ensino das Ciências no Atendimento Pedagógico Domiciliar. 91p. Dissertação (Mestrado em Formação Científica, Educacional e Tecnológica), Programa de Pós-Graduação em Formação Científica, Educacional e Tecnológica, Universidade Tecnológica Federal do Paraná. Curitiba, 2014a.

SILVA, Maria das Neves. As tecnologias como apoio à mediação pedagógica na classe hospitalar: desafios e possibilidades no ensino multisseriado. 147f. Dissertação (Mestrado em Educação), Faculdade de Educação, Programa de Pós-graduação em Educação, Universidade de Brasília - UnB, Brasília-DF, 2014b.

SOUSA, Sandra Santana Xavier de. Aprender é vida, ensinar é arte: atendimento pedagógico no setor pediátrico do HUPAA em uma abordagem complexa e multirreferencial. 203f. Dissertação (Mestrado em Educação Brasileira), Programa de PósGraduação em Educação Brasileira, Centro de Educação, Universidade Federal de Alagoas, Maceió-AL, 2011.

SOUZA, Denise Silva. Percepção de professores acerca da escolarização de alunos com anemia falciforme em Salvador-Bahia. 158f. Dissertação (Mestrado em Educação), Universidade Federal da Bahia, Faculdade de Educação, Salvador, 2013.

SEVERINO, Antônio Joaquim. Metodologia do trabalho científico. 24. ed. São Paulo: Cortez, 2016. 
STOCCHERO, Márcia Regina Soares. Atendimento psicopedagógico à criança e ao

Adolescente do hospital universitário Lauro Wanderley: implicações das práticas. $157 f$. Dissertação (Mestrado em Educação), Programa de Pós-Graduação em Educação, Centro de Educação, Universidade Federal da Paraíba, Paraíba-PB, 2012.

TAVARES, Luciani Bueno. A teoria da atividade como instrumento de análise da escola: 0 caso da EMAE. 149f. 2012. Dissertação (Mestrado em Educação), Faculdade de Educação, Instituto de Física, Instituto de Química e Instituto de Biociências, Universidade de São Paulo, São Paulo-SP, 2012.

WEBER, Carine Imperator. Entre educação, remédios e silêncios: trajetórias, discursos e políticas de escolarização de crianças hospitalizadas. Porto Alegre: UFRGS, 2009. $104 \mathrm{f}$. Dissertação (Mestrado em Educação), Programa de Pós-Graduação em Educação, Faculdade de Educação, Universidade Federal do Rio Grande do Sul, Porto Alegre, 2009.

XAVIER, Thaís Grilo Moreira. Escolarização de crianças e adolescentes hospitalizados: do direito à realidade. 110f. Dissertação (Mestrado em Enfermagem), Programa de PósGraduação em Enfermagem, Centro de Ciências da Saúde, Universidade Federal da Paraíba, João Pessoa-PB, 2012.

ZOMBINI, Edson Vanderlei. Classe hospitalar: uma estratégia para a promoção da saúde da criança. 152f. Dissertação (Mestrado em Saúde Pública), Programa de Pós-Graduação em Saúde Pública, Faculdade de Saúde Pública, Universidade de São Paulo, São Paulo-SP, 2011. 
ANEXO A - Teses e dissertações selecionadas para o estudo exploratório

\begin{tabular}{|c|c|c|c|}
\hline Ano & Autor (a) & Instituição & Título \\
\hline \multirow{5}{*}{2008} & $\begin{array}{l}\text { CARVALHO, A. } \\
\text { R. R. F. }\end{array}$ & PUC-SP & $\begin{array}{l}\text { A classe hospitalar sob o olhar de professores de um hospital } \\
\text { público infantil. }\end{array}$ \\
\hline & $\begin{array}{l}\text { BRANCO, R. F. } \\
\text { G.Y.R. }\end{array}$ & UFG & $\begin{array}{l}\text { Capacitação de professores de Classe Hospitalar em relação } \\
\text { professor-aluno/paciente na perspectiva balintiana. }\end{array}$ \\
\hline & $\begin{array}{l}\text { SILVA, J. M. de } \\
\text { A. }\end{array}$ & UNICAMP & $\begin{array}{l}\text { Um estudo sobre o processo de implementação de classes } \\
\text { hospitalares: o caso do Hospital Dr. Domingos Adhemar } \\
\text { Boldrini. }\end{array}$ \\
\hline & $\begin{array}{l}\text { KOWALSKI, R. } \\
\text { P. G. }\end{array}$ & PUC-PR & $\begin{array}{l}\text { Eurek@kids: uma experiência de uso de ambiente virtual de } \\
\text { aprendizagem no processo ensino-aprendizagem em contexto } \\
\text { hospitalar. }\end{array}$ \\
\hline & COVIC, A. N. & PUC-SP & $\begin{array}{l}\text { Aprendizagem da docência: um estudo a partir do } \\
\text { atendimento escolar hospitalar. }\end{array}$ \\
\hline \multirow{10}{*}{2009} & ASSIS, W. de & USP & $\begin{array}{l}\text { Atendimento pedagógico-educacional em hospitais: da } \\
\text { exclusão à inclusão social/escolar. }\end{array}$ \\
\hline & WEBER, C. I. & UFRGS & $\begin{array}{l}\text { Entre educação, remédios e silêncios: trajetórias, discursos e } \\
\text { políticas de escolarização de crianças hospitalizadas. }\end{array}$ \\
\hline & $\begin{array}{l}\text { CARVALHO, A. } \\
\text { de }\end{array}$ & UEL & A criança, o brincar e a aprendizagem no contexto hospitalar. \\
\hline & ALVES, A. B. L. & UFBA & $\begin{array}{l}\text { Implantação e avaliação de um conjunto de ações educativas } \\
\text { desenvolvidas junto a pacientes pediátricos internados: a } \\
\text { experiência do Hospital Manoel Novaes - BA. }\end{array}$ \\
\hline & $\begin{array}{l}\text { RODACOSKI, } \\
\text { G.C. }\end{array}$ & PUC-PR & $\begin{array}{l}\text { A mediação pedagógica em um ambiente virtual de } \\
\text { aprendizagem em contexto hospitalar. }\end{array}$ \\
\hline & FRANÇA, C. M. & PUC-PR & $\begin{array}{l}\text { Aspectos da formação do professor na mediação pedagógica } \\
\text { na utilizaçãao das tecnologias da informação e comunicação na } \\
\text { escolarização hospitalar. }\end{array}$ \\
\hline & $\begin{array}{l}\text { SILVA, M. C. R. } \\
\text { da }\end{array}$ & UFBA & $\begin{array}{l}\text { A criança e o adolescente enfermos como sujeito aprendentes: } \\
\text { representações de professores da rede regular de ensino no } \\
\text { município de Salvador-BA. }\end{array}$ \\
\hline & FORTE, L. T. & PUC-PR & $\begin{array}{l}\text { Mapa conceitual: um instrumento para a formação de } \\
\text { professores que trabalham com a escolarização no hospital } \\
\text { para uma prática inovadora. }\end{array}$ \\
\hline & COMIN, J. O. & UFSC & Os Saberes docentes na classe hospitalar. \\
\hline & GARCEZ, C. R. & PUC-PR & $\begin{array}{l}\text { Utilizando blog e suas ferramentas para auxiliar a integrar o } \\
\text { aluno-paciente à escola: um estudo de caso na área de ciências. }\end{array}$ \\
\hline \multirow{9}{*}{2010} & LIMA, L. F. & PUC-SP & Saberes necessários para atuação na pedagogia hospitalar. \\
\hline & $\begin{array}{l}\text { OLIVEIRA, F. A. } \\
\text { de M. }\end{array}$ & UNICAMP & $\begin{array}{l}\text { Projeto Pedagógico Hospitalar Escola Móvel - aluno específico } \\
=\text { cultura escolar e debate acadêmico (1989-2008). }\end{array}$ \\
\hline & MORAES, M. K. & USP & $\begin{array}{l}\text { As contribuições do atendimento educacional em ambiente } \\
\text { hospitalar a crianças que realizam tratamento oncológico. }\end{array}$ \\
\hline & $\begin{array}{l}\text { GEREMIAS, T. } \\
\text { M. F. }\end{array}$ & UFSC & O contexto da educação hospitalar nas narrativas de crianças. \\
\hline & KOHN, C. D. & UFS & $\begin{array}{l}\text { Ludoterapia: uma estratégia da pedagogia hospitalar na ala } \\
\text { pediátrica do Hospital Universitário da Universidade Federal de } \\
\text { Sergipe. }\end{array}$ \\
\hline & $\begin{array}{l}\text { CASTRO, A. D. } \\
\text { R. V. }\end{array}$ & USP & $\begin{array}{l}\text { Validação de conteúdo de sítio virtual sobre uso do brinquedo } \\
\text { na enfermagem pediátrica. }\end{array}$ \\
\hline & INVERNIZZI, L. & UFSC & $\begin{array}{l}\text { Educação física na classe hospitalar do Hospital Infantil Joana } \\
\text { de Gusmão: delineando uma proposta de ensino para os anos } \\
\text { iniciais. }\end{array}$ \\
\hline & $\begin{array}{l}\text { SANDRONI, G. } \\
\text { A. }\end{array}$ & UFSCar & $\begin{array}{l}\text { Classe hospitalar: a importância do acompanhamento } \\
\text { pedagógico para crianças e adolescentes. }\end{array}$ \\
\hline & ZOMBINI, E. V. & USP & Classe hospitalar: uma estratégia para a promoção da saúde da \\
\hline
\end{tabular}




\begin{tabular}{|c|c|c|c|}
\hline \multirow{9}{*}{2011} & & & criança. \\
\hline & $\begin{array}{l}\text { MORGADO, F. } \\
\text { M. }\end{array}$ & UnB & $\begin{array}{l}\text { Classes Hospitalares e seus recursos lúdicos: uma investigação } \\
\text { com os atores sociais envolvidos. }\end{array}$ \\
\hline & $\begin{array}{l}\text { CARDOSO, M. } \\
\text { R. }\end{array}$ & UnB & $\begin{array}{l}\text { Desafios e possibilidades da ludicidade no atendimento } \\
\text { pedagógico hospitalar. }\end{array}$ \\
\hline & $\begin{array}{l}\text { MASCARE- } \\
\text { NHAS, A. D. N. }\end{array}$ & UFBA & $\begin{array}{l}\text { Percepções de médicos sobre o papel do pedagogo no } \\
\text { trabalho com crianças hospitalizadas: o caso do Hospital das } \\
\text { Clínicas da UFBA. }\end{array}$ \\
\hline & $\begin{array}{l}\text { SOUSA, S. S.X. } \\
\text { de }\end{array}$ & UFAL & $\begin{array}{l}\text { Aprender é vida, ensinar é arte: atendimento pedagógico no } \\
\text { setor pediátrico do HUPAA em uma abordagem complexa e } \\
\text { multirreferencial. }\end{array}$ \\
\hline & $\begin{array}{l}\text { MORO, E. L. da } \\
\text { S. }\end{array}$ & UFRGS & $\begin{array}{l}\text { Ambientes virtuais de aprendizagem e recursos da web } 2.0 \text { em } \\
\text { contexto hospitalar: rompendo a exclusão temporária de } \\
\text { adolescentes com fibrose cística }\end{array}$ \\
\hline & $\begin{array}{l}\text { BONATO, C. A. } \\
\text { A. }\end{array}$ & UFV & $\begin{array}{l}\text { Estudo das representações de crianças internadas em hospital } \\
\text { sobre o adoecimento e a hospitalização em uma abordagem } \\
\text { piagetiana. }\end{array}$ \\
\hline & LOPER, A. A. & UEL & $\begin{array}{l}\text { O atendimento educacional de uma criança com necessidades } \\
\text { especiais na UTI: ressignificando vivências. }\end{array}$ \\
\hline & $\begin{array}{l}\text { SANTOS, D. F. } \\
\text { de Q. }\end{array}$ & PUC-GO & $\begin{array}{l}\text { Formação do professor para a pedagogia hospitalar na } \\
\text { perspectiva da educação inclusiva na rede municipal de } \\
\text { Goiânia. }\end{array}$ \\
\hline \multirow{11}{*}{2012} & $\begin{array}{l}\text { XAVIER, T. G. } \\
\text { M. }\end{array}$ & UFPB & $\begin{array}{l}\text { Escolarização de crianças e adolescentes hospitalizados: do } \\
\text { direito à realidade. }\end{array}$ \\
\hline & $\begin{array}{l}\text { NAZARETH, C. } \\
\text { A. L. }\end{array}$ & UFJF & $\begin{array}{l}\text { Educação hospitalar/domiciliar no município de Juiz de Fora - } \\
\text { Minas Gerais. }\end{array}$ \\
\hline & $\begin{array}{l}\text { PACCIULIO, A. } \\
\text { M. }\end{array}$ & USP & $\begin{array}{l}\text { Estratégias de enfrentamento do tratamento quimioterápico } \\
\text { na perspectiva de crianças com câncer hospitalizadas. }\end{array}$ \\
\hline & $\begin{array}{l}\text { ROCHA, S. M. } \\
\text { da }\end{array}$ & UFRN & $\begin{array}{l}\text { Narrativas infantis: o que nos contam as crianças de suas } \\
\text { experiências no hospital e na classe hospitalar. }\end{array}$ \\
\hline & SANTANA, C. & UFES & Práticas de leitura em um hospital do município de Vitória, ES. \\
\hline & $\begin{array}{l}\text { SALDANHA, G. } \\
\text { M. M. M. }\end{array}$ & UFPA & $\begin{array}{l}\text { A educação escolar hospitalar: práticas pedagógicas docentes } \\
\text { com crianças em tratamento oncológico no Hospital Ophir } \\
\text { Loyola em Belém-PA. }\end{array}$ \\
\hline & $\begin{array}{l}\text { STOCCHERO, } \\
\text { M.R.S. }\end{array}$ & UFPB & $\begin{array}{l}\text { Atendimento psicopedagógico à criança e ao adolescente do } \\
\text { Hospital Universitário Lauro Wanderley: implicações das } \\
\text { práticas. }\end{array}$ \\
\hline & TAVARES, L. B. & USP & $\begin{array}{l}\text { A teoria da atividade como instrumento de análise da escola: o } \\
\text { caso da EMAE. }\end{array}$ \\
\hline & SILVA, G. C. da & PUC-PR & $\begin{array}{l}\text { A formação de professores e a utilização das mesas } \\
\text { educacionais como meio pedagógico integrado à proposta de } \\
\text { escolarização em contexto hospitalar. }\end{array}$ \\
\hline & LEITE, T. M. C. & UNICAMP & $\begin{array}{l}\text { Trabalho do enfermeiro com crianças hospitalizadas e o uso do } \\
\text { brinquedo terapêutico. }\end{array}$ \\
\hline & MEINEM, C. V. & UFSC & Conteúdos subjetivos da docência e a classe hospitalar \\
\hline \multirow{5}{*}{2013} & $\begin{array}{l}\text { MAZER- } \\
\text { GONÇALVES, S. } \\
\text { M. }\end{array}$ & UFSCar & $\begin{array}{l}\text { Construção de uma proposta de formação continuada para } \\
\text { professores de classe hospitalar. }\end{array}$ \\
\hline & BATISTA, C. A. & UnB & $\begin{array}{l}\text { O uso do computador em rede telemática no processo de } \\
\text { ensino e aprendizagem em classe-hospitalar: o PRO-UCA e o } \\
\text { Eduquito promovendo a aprendizagem do aluno enfermo. }\end{array}$ \\
\hline & LOIOLA, F. C. F. & UFPE & $\begin{array}{l}\text { Subsídios para a educação hospitalar na perspectiva da } \\
\text { educação inclusiva. }\end{array}$ \\
\hline & $\begin{array}{l}\text { GIANNONI, R. } \\
\text { M. }\end{array}$ & PUC-SP & $\begin{array}{l}\text { A Escola Hospitalar do Hospital A. C. Camargo: uma experiência } \\
\text { de humanização narrada por sua fundadora. }\end{array}$ \\
\hline & CARMO, R. S. & UFBA & Práticas musicais em classe hospitalar: um estudo na rede \\
\hline
\end{tabular}




\begin{tabular}{|c|c|c|c|}
\hline & & & municipal de Salvador. \\
\hline & $\begin{array}{l}\text { GUEUDEVIL, E, } \\
\text { R. S. }\end{array}$ & UFBA & $\begin{array}{l}\text { O papel da classe hospitalar na atenção terapêutica de alunos- } \\
\text { pacientes com doença crônica progressiva: o caso da } \\
\text { mucopolissacaridose. }\end{array}$ \\
\hline & $\begin{array}{l}\text { MOURA, I. F. } \\
\text { de }\end{array}$ & FIOCRUZ & $\begin{array}{l}\text { O lúdico no hospital: um estudo teórico sobre atividades com } \\
\text { crianças. }\end{array}$ \\
\hline & $\begin{array}{l}\text { SCAGGION, L. } \\
\quad \text { R. E. }\end{array}$ & UNICAMP & $\begin{array}{l}\text { "Mas eu sabe tudo": compreendendo o mundo-vida da criança } \\
\text { hospitalizada na unidade de terapia intensiva pediátrica por } \\
\text { meio do brinquedo terapêutico. }\end{array}$ \\
\hline & $\begin{array}{l}\text { MORAES, M. S. } \\
\text { de }\end{array}$ & UFS & $\begin{array}{l}\text { Brincando e sendo feliz: a pedagogia hospitalar como proposta } \\
\text { humanizadora no tratamento de crianças hospitalizadas. }\end{array}$ \\
\hline & $\begin{array}{l}\text { SOUZA, D. S. } \\
\text { de }\end{array}$ & UFBA & $\begin{array}{l}\text { Percepção de professores acerca da escolarização de alunos } \\
\text { com anemia falciforme em Salvador-Bahia. }\end{array}$ \\
\hline & PRATES, C. C. & UFRGS & $\begin{array}{l}\text { Bri(n)coleur: uma experiência de pesquisa e formação em } \\
\text { pedagogia hospitalar. }\end{array}$ \\
\hline \multirow{8}{*}{2014} & SILVA, M. V. G. & UTFPR & $\begin{array}{l}\text { A utilização de jogos didáticos em novos segmentos da } \\
\text { educação: a prática pedagógica do professor no ensino das } \\
\text { ciências no atendimento pedagógico domiciliar. }\end{array}$ \\
\hline & SILVA, A. R. da & UFMT & $\begin{array}{l}\text { O ensino de ciências na classe hospitalar: uma reflexão sobre a } \\
\text { experiência do HUJM - UFMT. }\end{array}$ \\
\hline & $\begin{array}{l}\text { SILVA, M. das } \\
\text { N. }\end{array}$ & UnB & $\begin{array}{l}\text { As tecnologias como apoio à mediação pedagógica na classe } \\
\text { hospitalar: desafios e possibilidades no ensino multisseriado. }\end{array}$ \\
\hline & $\begin{array}{l}\text { SANT'ANA, A. } \\
\text { S. C. }\end{array}$ & UFES & $\begin{array}{l}\text { O ser da presença da docência com o dispositivo tablet pc e as } \\
\text { teias educacionais de aprendizagens inclusivas na } \\
\text { [psico]pedagogia social hospitalar. }\end{array}$ \\
\hline & $\begin{array}{l}\text { GONÇALVES, } \\
\text { M. F. de C.P. }\end{array}$ & UFSC & $\begin{array}{l}\text { O serviço de educação infantil - HU/UFSC frente à resolução } \\
\text { CNE/CEB N }{ }^{\circ} \text { 01/2011 (BRASIL, 2011a): desafios e perspectivas. }\end{array}$ \\
\hline & JESUS, A. S. de & UFBA & $\begin{array}{l}\text { Significados sobre a doença e a hospitalização na infância } \\
\text { contidos em livros para crianças. }\end{array}$ \\
\hline & $\begin{array}{l}\text { GARCIA-SCHI } \\
\text { NZARI, N. R. }\end{array}$ & USP & $\begin{array}{l}\text { Análise do brincar de faz de conta de crianças pré-escolares } \\
\text { com câncer. }\end{array}$ \\
\hline & BRAGIO, J. & UFES & $\begin{array}{l}\text { O sentido de ser educadora das/nas brinquedotecas do } \\
\text { hospital infantil de Vitória/ES: um estudo a partir dos conceitos } \\
\text { de experiência, narrativa e cuidado. }\end{array}$ \\
\hline \multirow{4}{*}{2015} & ALVES, P.P. & UFMT & $\begin{array}{l}\text { O papel do jogo nos processos de aprendizagem de crianças } \\
\text { hospitalizadas. }\end{array}$ \\
\hline & $\begin{array}{l}\text { MAGALHÃES, } \\
\text { M. V.S. }\end{array}$ & UnB & $\begin{array}{l}\text { Vestindo vivências: a educação em artes visuais na classe } \\
\text { hospitalar. }\end{array}$ \\
\hline & BATISTA, V. & PUC-SP & $\begin{array}{l}\text { Ensino da linguagem escrita no contexto da classe hospitalar: } \\
\text { um enfoque metalinguístico. }\end{array}$ \\
\hline & LUCON, C. B. & UFBA & $\begin{array}{l}\text { Representações docentes: o olhar para o aluno com } \\
\text { mucopolissacaridose tipo VI do município de Monte Santo-BA. }\end{array}$ \\
\hline \multirow{6}{*}{2016} & $\begin{array}{l}\text { HOCHMULLER, } \\
\text { C.S. de O }\end{array}$ & UNIJUÍ & $\begin{array}{l}\text { Experiências de crianças hospitalizadas: um estudo em um } \\
\text { hospital do município de Cruz Alta - RS. }\end{array}$ \\
\hline & $\begin{array}{l}\text { OLIVEIRA, R. C. } \\
\text { A. M. de }\end{array}$ & UFRN & $\begin{array}{l}\text { Narrativas de aprendizagens ao longo da vida: uma pesquisa- } \\
\text { ação-formação com professoras de classes hospitalares. }\end{array}$ \\
\hline & $\begin{array}{l}\text { MARES, T. F. } \\
\text { de } L .\end{array}$ & UNIOESTE & $\begin{array}{l}\text { O serviço de atendimento à rede de escolarização hospitalar } \\
\text { do Hospital Universitário do Oeste do Paraná de Cascavel - PR: } \\
\text { um estudo sobre os adolescentes atendidos na ala de } \\
\text { desintoxicação. }\end{array}$ \\
\hline & $\begin{array}{l}\text { BATAGLION, G. } \\
\text { A. }\end{array}$ & UFSC & O lúdico na reabilitação de crianças com deficiência. \\
\hline & $\begin{array}{l}\text { PASTEGA, M. } \\
\text { G. }\end{array}$ & UFSCar & A qualidade de vida da criança durante a internação hospitalar. \\
\hline & $\begin{array}{l}\text { BONFIM, E. L. } \\
\text { S. }\end{array}$ & UNIFESP & $\begin{array}{l}\text { Formação do pedagogo para atuar na classe hospitalar: } \\
\text { desafios e perspectivas. }\end{array}$ \\
\hline
\end{tabular}




\begin{tabular}{|c|c|c|c|}
\hline \multirow{7}{*}{2017} & LIMA, F. C. de & USP & $\begin{array}{l}\text { Caracterização do atendimento escolar oferecido às crianças e } \\
\text { aos adolescentes internados em um hospital terciário. }\end{array}$ \\
\hline & PACCO, A. F. R. & UFSCar & $\begin{array}{l}\text { Panorama das classes hospitalares brasileiras: formação e } \\
\text { atuação docente, organização e funcionamento. }\end{array}$ \\
\hline & PEREIRA, J. S. & UFMG & $\begin{array}{l}\text { Crianças hospitalizadas com leucemia: aspectos } \\
\text { neuropsicológicos, comportamentais, clínicos e educacionais } \\
\text { na classe hospitalar. }\end{array}$ \\
\hline & JESUS, E. M. de & PUC-GO & $\begin{array}{l}\text { Desafios do atendimento pedagógico hospitalar/domiciliar em } \\
\text { Goiás: gênero e docência no olhar dos/as agentes } \\
\text { envolvidos/as. }\end{array}$ \\
\hline & $\begin{array}{l}\text { MIRANDA, P. } \\
\text { C. C. de }\end{array}$ & USP & $\begin{array}{l}\text { Música e jogos sonoros: a experiência lúdica no ambiente } \\
\text { hospitalar infantil humanizado. }\end{array}$ \\
\hline & $\begin{array}{l}\text { BATISTA, A. da } \\
\text { S. }\end{array}$ & UnB & $\begin{array}{l}\text { Escolarização de crianças com doenças crônicas: "eu presto } \\
\text { atenção no que eles dizem, mas eles não dizem nada". }\end{array}$ \\
\hline & $\begin{array}{l}\text { CAMPOS, S. M. } \\
\text { S. de }\end{array}$ & USP & $\begin{array}{l}\text { O brincar de faz de conta de crianças com câncer que se } \\
\text { submetem ao processo de quimioterapia. }\end{array}$ \\
\hline
\end{tabular}

Fonte: Elaborado pelos autores.

Recebido em: 24/05/2020

Revisões requeridas em: 23/10/2020

Aprovado em: 22/02/2021

Universidade do Estado de Santa Catarina - UDESC

Programa de Pós-Graduação em Educação - PPGE

Revista Linhas

Volume 22 - Número 48 - Ano 2021

revistalinhas@gmail.com 